\title{
Association of the pre-monsoon thermal field over north India and the western Tibetan Plateau with summer monsoon rainfall over India
}

\author{
S. D. Bansod, S. Fadnavis, and S. P. Ghanekar \\ Indian Institute of Tropical Meteorology, Pune, India \\ Correspondence to: S. D. Bansod (erp@tropmet.res.in) \\ Received: 25 February 2015 - Revised: 30 June 2015 - Accepted: 9 August 2015 - Published: 25 August 2015
}

\begin{abstract}
In this paper, interannual variability of tropospheric air temperatures over the Asian summer monsoon region during the pre-monsoon months is examined in relation to Indian summer monsoon rainfall (ISMR; June to September total rainfall). For this purpose, monthly gridpoint temperatures in the entire troposphere over the Asian summer monsoon region and ISMR data for the period 19492012 have been used. Spatial correlation patterns are investigated between the temperature field in the lower tropospheric levels during May over the Asian summer monsoon region and ISMR. The results indicate a strong and significant northwest-southeast dipole structure in the spatial correlations over the Indian region, with highly significant positive (negative) correlations over the regions of north India and the western Tibetan Plateau region - region R1 (north Bay of Bengal: region R2). The observed dipole is seen significantly up to a level of $850 \mathrm{hPa}$ and eventually disappears at $700 \mathrm{hPa}$. Thermal indices evaluated at $850 \mathrm{hPa}$ level, based on average air temperatures over the north India and western Tibetan Plateau region $\left(\mathrm{TI}_{1}\right)$ and the north Bay of Bengal region $\left(\mathrm{TI}_{2}\right)$ during May, show a strong, significant relationship with the ISMR. The results are found to be consistent and robust, especially in the case of $\mathrm{TI}_{1}$ during the period of analysis. A physical mechanism for the relationship between these indices and ISMR is proposed. Finally the composite annual cycle of tropospheric air temperature over R1 during flood/drought years of ISMR is examined. The study brings out the importance of the $\mathrm{TI}_{1}$ in the prediction of flood/drought conditions over the Indian subcontinent.
\end{abstract}

Keywords. History of geophysics (atmospheric sciences)

\section{Introduction}

The Asian summer monsoon (ASM), a part of the global monsoon system, is considered to be an atmospheric response to seasonal changes in a land-sea thermal contrast, induced by the annual cycle of the solar zenith angle. A number of studies (Mohanty et al., 1983; Pearce and Mohanty, 1984; Li and Yanai, 1996; Liu and Yanai, 2001) also referred to the land-ocean thermal contrast as being a primary driver for the Asian monsoon - a seasonal-scale sea breeze circulation. As part of ASM, summer monsoon circulation over India is a unique example of such seasonal-scale circulation and also thought of as emanating in a similar way to a gigantic land-sea breeze.

The summer monsoon circulation over India normally gets established by the end of May over the Indian seas and south peninsular India, and prevails till the end of September. During the period of the Indian summer monsoon season, strong heat troughs form over land areas surrounding the Arabian Sea, particularly over areas of north India, Pakistan, Iran and Saudi Arabia. At the same time, high mountains like Himalaya, to the north, seal off the cold air outbreaks (Mahajan et al., 1989). In the past, the relationship between tropospheric temperature in pre-monsoon months and the Indian summer monsoon rainfall (ISMR: June to September total rainfall) has been examined in several studies (Verma, 1982; Mooley and Paolino, 1988; Parthasarathy et al., 1990; Rajeevan et al., 1998; Kothawale and Rupa Kumar, 2002). Verma (1982) pointed out that years with a cooler upper troposphere over north and northwest regions of India during pre-monsoon months (April and May) were generally associated with normal/below-normal activities of the subsequent Indian summer monsoon. In the 1980s, Moo- 
ley and Paolino (1988) examined the relationship between the monthly surface thermal field over India during the premonsoon months and summer monsoon rainfall. They reported that the mean minimum temperature in the month of May over the south Gujarat region showed a highly significant positive correlation with subsequent monsoon rainfall. Using conventional data (station observations) over the Indian region, Parthasarathy et al. (1990) showed that upper air temperature during the pre-monsoon season over west central India can be useful in the prediction of ISMR. Also, using well distributed radiosonde station data over India, Kothawale and Rupa Kumar (2002) reported that the tropospheric temperature anomaly, composites of excess (deficient) monsoon rainfall years, showed pronounced positive (negative) anomalies during the month of May. Liu and Yanai (2001) showed that the summer rainfall across the whole of India is positively correlated to the mean tropospheric temperature at $200-700 \mathrm{hPa}$ averaged over Eurasia in summer. Hence the above studies have shown that the premonsoon thermal field over the Indian landmass affects the overall performance of the summer monsoon rainfall over India. However, most of these studies are based either on station observations over the Indian subcontinent or on surface air temperature indexes averaged over the whole large area.

Studies have also pointed out that anomalies at higher latitudes are considered to influence the variations in the Asian monsoon (Kripalani et al., 1997; Bansod et al., 2005; Ding and Wang, 2007; Fujinami and Yasunari, 2009; Krishnan et al., 2009). A study by Kripalani et al. (1997) showed that the west Pacific teleconnection pattern in the mid-troposphere is significantly related to the ISMR. Also Bansod et al. (2005) pointed out that mid-tropospheric height over the eastern tropical Pacific Ocean during winter plays an important role in modulating the ISMR. Based on the geopotential height data, Watanabe and Yamazaki (2012) suggested that the western Tibetan Plateau region has an important effect on the intensity of the south Asian monsoon.

In India, summer monsoon is the lifeblood of the agricultural population which shows considerable interannual variability. The large-scale deficit/excess rainfall over the Indian subcontinent not only affects life but also influences the economy of the country. Hence even in present days, identification of a precursor for flood/drought-type conditions over India has an enormous importance for the Indian meteorological community. Also, as discussed earlier, past studies were either based on conventional measurements or even if they were based on model data, a detailed analysis of interannual variation of the thermal field over the ASM region in relation to ISMR is not reported adequately, as well as a detailed composite analysis of the thermal field also not being reported. Taking into consideration all these facts, in this paper, using global NCEP(National Center for Environmental Prediction)-based model data, we examine a detailed analysis of interannual variation of the thermal field over the ASM region for various tropospheric heights in relation to
ISMR. Using a composite analysis technique, we have further demonstrated that this relationship may be useful in the prediction of flood/drought conditions over the Indian subcontinent.

This paper is organized as follows: the data and methodology utilized are discussed in Sect. 2. A detailed examination of the relationship between air temperature and the ISMR and the discussion of the physical linkage of the relationship observed is made in Sect. 3, and $t$ value statistics based on the difference of monthly composite temperature anomalies for flood and drought years over R1 $\left(25\right.$ to $40^{\circ} \mathrm{N}$ and 70 to $80^{\circ}$ E) are discussed in Sect. 4. Finally, a summary of the study is presented in Sect. 5 .

\section{Data and methodology}

Monthly mean NCEP/NCAR (National Center for Atmospheric Research) reanalyzed grid-point temperature, wind and geopotential height data at $2.5^{\circ}$ lat $\times 2.5^{\circ}$ long grid interval, for standard levels in the troposphere for the period 1949-2012 (Kalney et al., 1996) are used in the analysis, taken from http://www.esrl.noaa.gov/psd/data/gridded/data. ncep.reanalysis $2 . h t m l$. In addition, ISMR data extracted from the IITM website (www.tropmet.res.in) for the same period are also used.

The thermal structure over the ASM domain for the entire troposphere is obtained from air temperature data. The circulation changes related to warm years $(1953,1956,1959$, 1961, 1970, 1988, 2007 and 2011) and cold years (1968, 1972, 1979, 1982, 1987, 1992, 2002 and 2009) are analyzed from zonal and meridional wind at $850 \mathrm{hPa}$. The selected sets of years are chosen such that they consist of contrasting years of ISMR as well as exhibit consistent warm and cold May mean temperatures in the entire lower tropospheric column over the selected region. In an earlier study, Mason and Goddard (2001) defined criteria for cold and warm years. In their criteria, the warm (cold) years are defined when the normalized temperature values exceed (are below) 1 standard deviation (SD). of the selected warm and cold years of the present study follow this criterion.

The zonal and meridional winds and geopotential height at $200 \mathrm{hPa}$ level have also been used to explain the physical significance of the relationship between the thermal index $\left(\mathrm{TI}_{1}\right.$, deduced in this study explained in Sect. 3.2) and the ISMR.

In order to study the relationship between the air temperature field over the ASM domain and the ISMR, and to explore the possible physical linkage between them, the following approaches have been adopted.

i. Simple linear correlation analysis is performed to reveal the possible relationship between the air temperature field over the given domain and the ISMR.

ii. The technique of running windows of different width has been applied to test the consistency/stability of the relationship. 

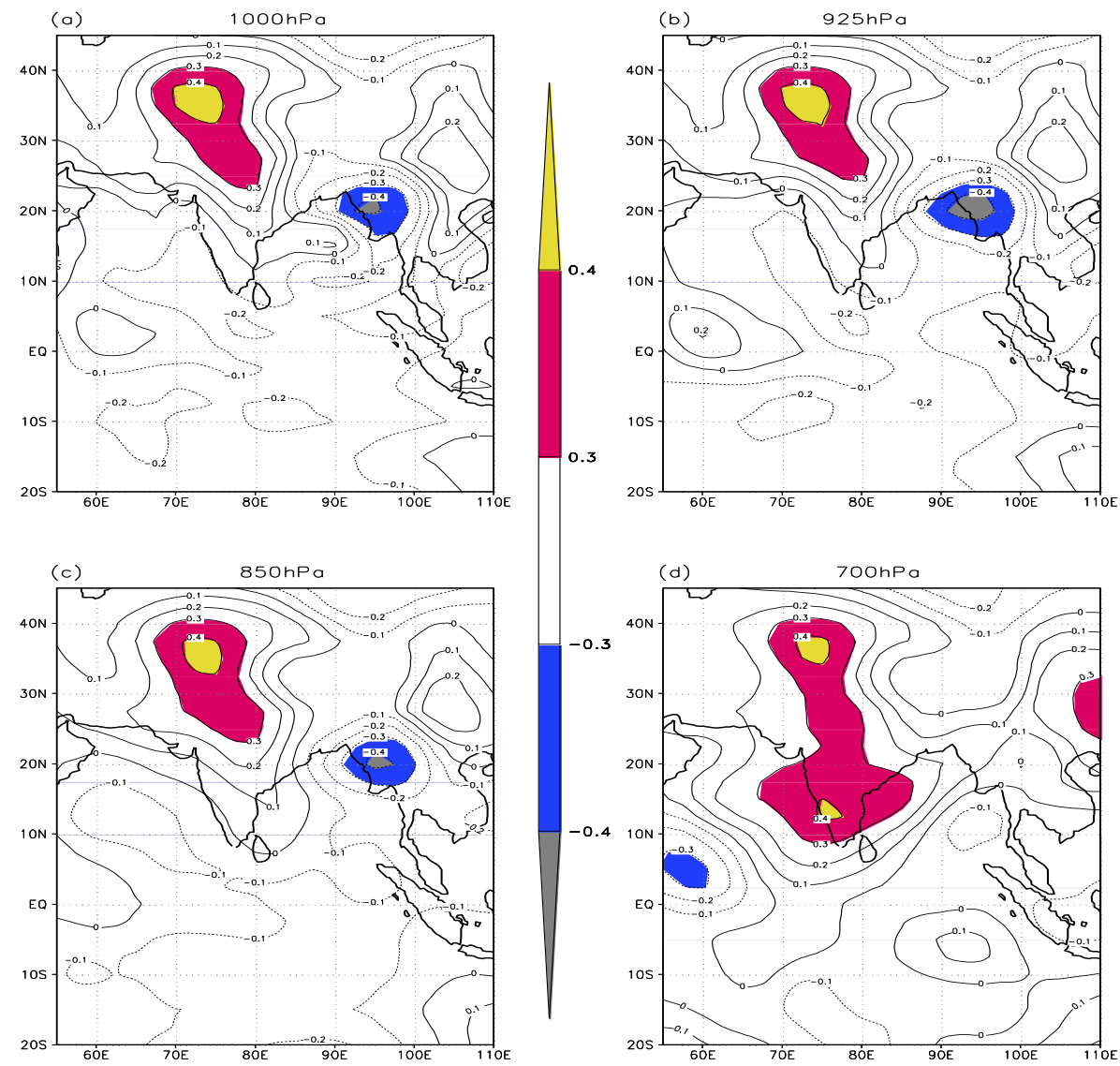

Figure 1. Spatial distribution of the correlation coefficients of ISMR with air temperature over Asian region for (a) $1000 \mathrm{hPa}$ (b) $925 \mathrm{hPa}$ (c) $850 \mathrm{hPa}$ and (d) $700 \mathrm{hPa}$ for May. Positive (negative) correlations, significant at $1 \%$ level, are indicated by yellow (gray) shade.

iii. To understand the physical linkage of the relationship between ISMR and temperature, composite winds and geopotential heights are analyzed for warm and cold years.

In the present analysis, a year is defined as being a flood year if ISMR $>\mathrm{M}+1 \sigma$ and as being a drought year if ISMR $<\mathrm{M}-1 \sigma$, where $\mathrm{M}$ and $\sigma$ are the mean and the $\mathrm{SD}$ of ISMR. As per these criteria, flood years are: 1955, 1956, 1959, 1961, 1970, 1975, 1983, 1994 and 2007, and drought years are: 1951, 1965, 1966, 1972, 1979, 1982, 1986, 1987, 2002 and 2009. The composite annual cycle of temperature over significant regions during flood/drought monsoon years of the ISMR are examined in detail for the prediction of flood/drought conditions over the Indian subcontinent.

The Student's $t$ test has been applied to test the difference in mean temperature over the specified regions during May in flood and drought years. The critical value of the Student's $t$ test with a $95 \%$ confidence level is 1.75 .

\section{Results and discussion}

\subsection{Relationship between air temperature and ISMR}

To explore the air temperature-ISMR relationship during pre-monsoon months, we have computed the spatial correlation between the thermal field over the ASM region for each month of the pre-monsoon season (March through May) at standard levels in the troposphere and ISMR. It was noticed that the spatial correlation coefficients $(\mathrm{CC})$ between air temperature field and ISMR were weak and insignificant during March to April for all the levels, while for the month of May, CC is found to be significant for lower tropospheric levels and hence only these results are presented. Figure 1 gives the correlation patterns for May, for the levels 1000 to $700 \mathrm{hPa}$. The statistical significance of these CCs is tested using the Student's $t$ distribution. The positive correlation values, which are significant at $1 \%(5 \%)$, are shown by yellow (red), while negative CCs, significant at $1 \%(5 \%)$, are shown by a gray (blue) shade in the Figure. The correlation map for $1000 \mathrm{hPa}$ (Fig. 1a) shows a northwest-southeast dipole-type pattern with significant positive correlation observed within a domain bounded by 25 to $40^{\circ} \mathrm{N}$ and 70 to $80^{\circ} \mathrm{E}$ (region 


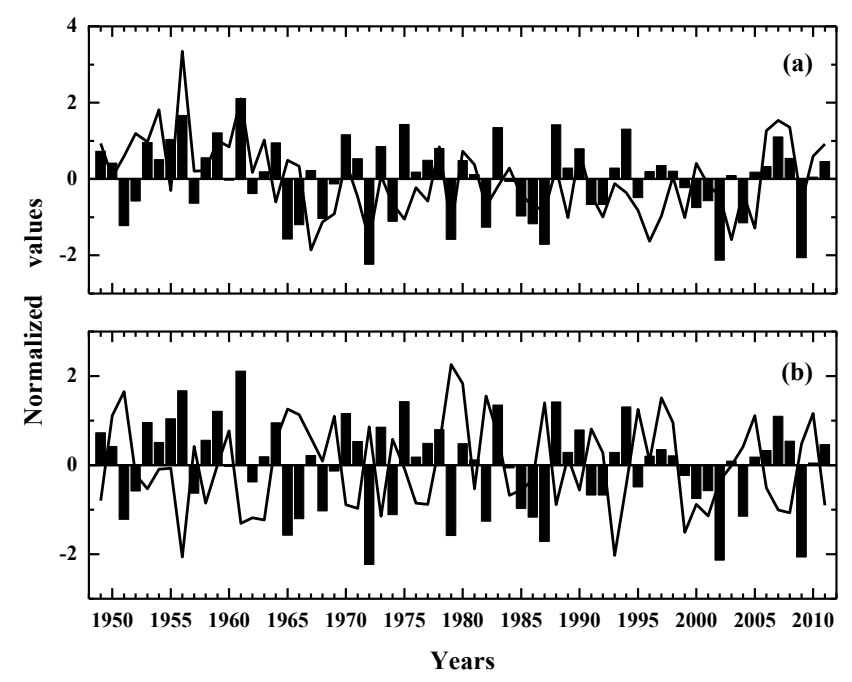

Figure 2. Interannual variability of the normalized values of (a) $\mathrm{TI}_{1}$ and ISMR and (b) $\mathrm{TI}_{2}$ and ISMR. Index one and Index two are shown by solid curves while ISMR is shown by histogram.

$\mathrm{R} 1$ ), and negative correlation over 17.5 to $22.5^{\circ} \mathrm{N}$ and 90 to $100^{\circ} \mathrm{E}$ (region $\mathrm{R} 2$ ). The dipole persists and remains anchored over the same region with a little bit of expansion of significant correlation area for $925 \mathrm{hPa}$ (Fig. 1b). The dipole was found to be strongest in the case of $850 \mathrm{hPa}$ (Fig. 1c). At a level of $700 \mathrm{hPa}$, the significant positive correlations persist all over India, excluding the northwest and northeast regions (Fig. 1d). The strongest significant dipole-type relationship at $850 \mathrm{hPa}$ level during May indicates that during flood (drought) years, above (below)-normal temperatures are witnessed over R1, while the reverse is noticed in case of R2. In an earlier study, Mohanty et al. (2002) reported that positive (negative) surface temperature anomalies occur over the northwest Indian (Bay of Bengal) region during the excess rainfall years over India. The positive temperature anomaly over R1 seems to be due to excess pre-monsoon heating, whereas the negative temperature anomaly over R2 is due to excess cooling in May.

\subsection{Interannual variability of indices and ISMR}

As discussed in the previous section, since the dipole-type relationship between ISMR and air temperature is found to be strongest and significant at $850 \mathrm{hPa}$ during May, we have computed the two thermal indices viz., (1) $\mathrm{TI}_{1}$ and (2) $\mathrm{TI}_{2}$, based on the areal average air temperature over R1 and R2, respectively, for the month of May. The $\mathrm{TI}_{1}$ appears to be the best, showing the highest correlation coefficient with ISMR (CC was 0.48 ) followed by that of $\mathrm{TI}_{2}$ (CC was 0.41 ). The positive relationship between $\mathrm{TI}_{1}$ and the ISMR suggests that the above (below) normal activity of ISMR is related to warmer (cooler) temperature in May over R1, while the reverse is seen in the case of $\mathrm{TI}_{2}$. The interannual variability of ISMR as well as that of the thermal indices $\left(\mathrm{TI}_{1}\right.$ and
$\mathrm{TI}_{2}$ ) is presented in Fig. 2. It can be concluded that the interannual variability of ISMR is in phase with the $\mathrm{TI}_{1}$, while it is out of phase with $\mathrm{TI}_{2}$. This is again in agreement with the high positive (negative) correlation between the $\mathrm{TI}_{1}\left(\mathrm{TI}_{2}\right)$ and ISMR.

The physical linkage of the thermal $\mathrm{TI}_{1}$ and $\mathrm{TI}_{2}$ with ISMR is proposed as follows. The primary contributor to the positive thermal $\mathrm{TI}_{1}$ may be the excess heating in May over R1. Kripalani et al. (2003) showed that an inverse relationship exists between snow cover depth over the western Himalayan region during May and ISMR. From this, it can be inferred that during above-normal years of ISMR, less snow cover depth over west Himalayan region in the month of May is observed. This may lead to relatively warmer air temperatures over the region (R1 in the present study) resulting in positive $\mathrm{TI}_{1}$, favoring the above-normal ISMR, while negative $\mathrm{TI}_{2}$ may be due to excess cooling in May over R2. Based on Outgoing Longwave Radiation (OLR) data, Prasad et al. (2000) showed that, when the north Bay of Bengal region (R2 in present study) experiences more convective activities during May, the subsequent ISMR happens to be above normal. Such frequent convective activities induce a sudden drop in temperature and rise in pressure due to descending cold air from aloft. Hence the cooling over R2 may be due to frequent formation of pre-monsoon thunderstorm/squall activities over the region and favors abovenormal ISMR. It is also observed through earlier studies that when the number of cyclones forming over the Bay of Bengal region in pre-monsoon season is increased (Fadnavis et al., 2011, 2014), the subsequent ISMR is found to be above normal (Krishna, 2009; Ng and Chan, 2012). During premonsoon months, most of the cyclones, formed in Bay of Bengal region, show north-east movement and hit the land in the north of the Bay of Bengal region (Fadnavis et al., 2014). Occurrence of heavy rainfall activity associated with these events may further lead to cooling over the region (R2 in present study) and favoring for above-normal ISMR.

In order to strengthen the physical linkage between the $\mathrm{TI}_{1}$ and ISMR, we investigate the composite analysis of $200 \mathrm{hPa}$ wind anomalies for the years of positive and negative $\mathrm{TI}_{1}$ i.e., the years with warm and cold temperature anomalies over R1 respectively. Figure 3a and b present composites of $200 \mathrm{hPa}$ wind anomaly in the month of May for warm and cold years (given in Sect. 2), respectively. The figure depicts anticyclonic (cyclonic) winds during warm (cold) years over the region of northwest India and neighboring regions. In an earlier study, Joseph and Srinivasan (1999) have also observed almost similar features in the mean $200 \mathrm{hPa}$ wind anomaly field and they found that when anticyclonic (cyclonic) wind field is observed in May over northwest India, then subsequent ISMR may be seen as a wet (dry) year. Based on the analysis of $200 \mathrm{hPa}$ meridional wind anomalies, they also noted a train of large amplitude waves (Rossby waves) with spatial phase difference of about $20^{\circ}$ longitude between wet and dry years of ISMR. By carrying out similar analysis we also found 
(a) $200 \mathrm{hPa}$ Composite wind anomaly for warm years

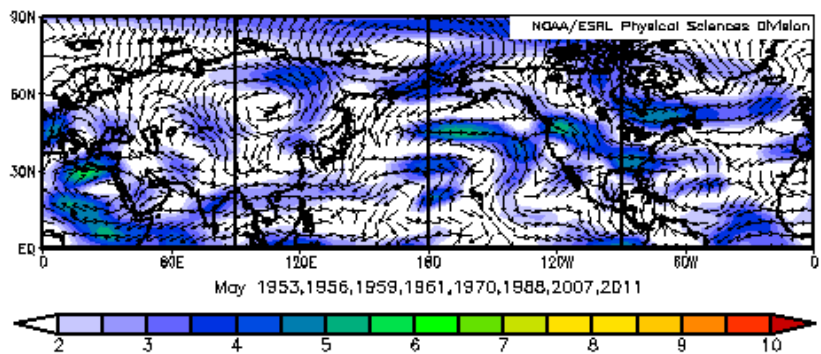

(b) $200 \mathrm{hPa}$ Composite wind anomaly for cold years

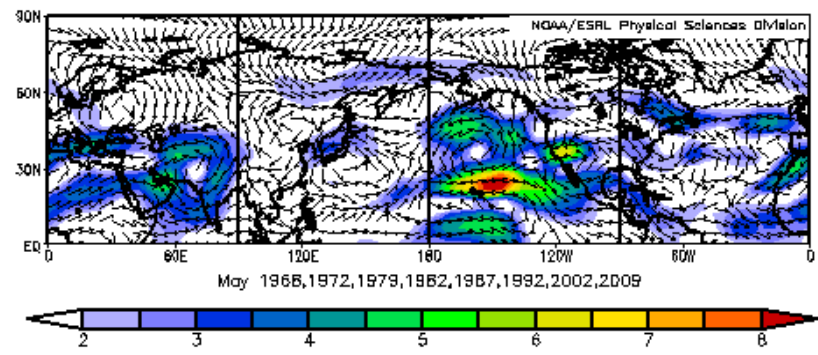

Figure 3. Composites of global northern hemispheric $200 \mathrm{hPa}$ wind anomalies for the month of May for selected (a) warm and (b) cold years.

similar features for warm and cold years (figure not shown). From Fig. $3 b$ it can also be inferred that the presence of cyclonic wind anomalies in May over the region R1 may lead to incursion of cold air from northern latitudes over the north Indian region. This may further adversely affect the heat low, resulting in subsequent below normal ISMR. Also a study by Krishnan et al. (2009) showed that on intraseasonal to interannual timescales, the anomalous mid-latitude circulation over western, central and eastern Asia can induce anomalous cooling in the middle and upper troposphere through cold air advection. The intrusion of such extra-tropical wind into northwestern India and Pakistan can in turn weaken the monsoon flow.

Fig. 4a and b present composites of $200 \mathrm{hPa}$ geopotential height anomalies in the month of May for warm and cold years. High positive (negative) anomalies are observed during the composites of warm (cold) years over the region of northwest India and neighboring regions, which indicates the presence of strong anticyclonic (cyclonic) anomalies over the region. Based on the results of the geopotential height index over the region of Afghanistan and the western Tibetan Plateau, Watanabe and Yamazaki (2012) suggested that the upper level anticyclone over the region generates an anomalous descent over the Thar desert region. They also mentioned that the upper level anomalous anticyclone promotes the development of a heat low through adiabatic heating, associated with strong subsidence and near-surface sensible heating. In a similar analogy, the stronger anomalous anti- (a) $200 \mathrm{hPa}$ Composite Geopotential height anomaly for warm years

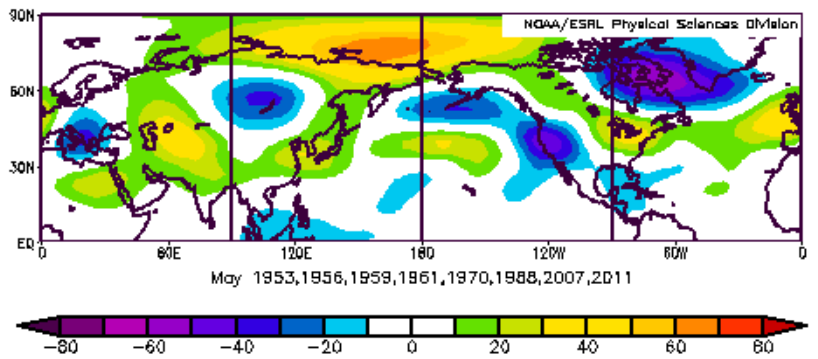

(b) $200 \mathrm{hPa}$ Composite Geopotential height anomaly for cold years

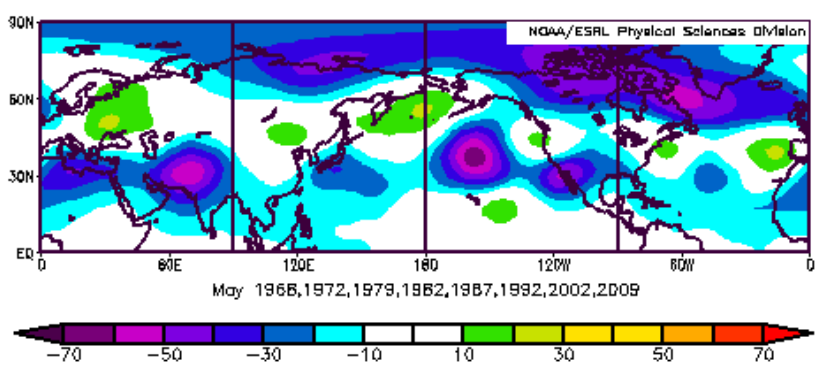

Figure 4. Composites of global northern hemispheric $200 \mathrm{hPa}$ geopotential height anomalies for the month of May for selected (a) warm and (b) cold air years.

cyclone seen over region R1 (Fig. 4a) during warm years may lead to intensification of the heat low over northwest India and the adjoining areas. This further leads to an abovenormal ISMR.

From Fig. 4a and b, zonal wave trains, consisting of alternating zones of high and low thickness values of geopotential height running over the mid-latitudes, are seen for warm and cold years. The striking difference is the high thickness values (Fig. 4a) and anticyclonic circulation (Fig. 3a) which are seen to appear over the region of northwest India during the warm years are noticed to have been replaced by low thickness values (Fig. 4b) and cyclonic circulation (Fig. 3b) over the same region in cold years. This might thus have taken place due to a relative shift of wave train based on the composites of warm and cold years and is consistent with the earlier results of Joseph and Srinivasan (1999).

\subsection{Stability of the relationship between ISMR and thermal indices}

The relationship between the temperature anomalies and ISMR should be tested for its stability before using it in prediction of the ISMR, since a recent study by Prasad et al. (2000) found that some predictors of the ISMR have been losing the power of prediction of ISMR during recent decades. In order to test the consistency and stability of the relationship between the thermal indices with the ISMR, we 


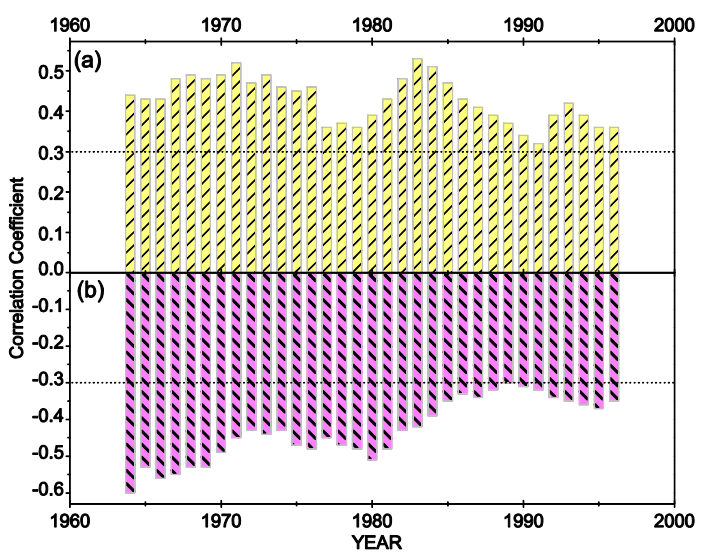

Figure 5. Variation of 31 year sliding correlation coefficient between (a) $\mathrm{TI}_{1}$ and ISMR and (b) $\mathrm{TI}_{2}$ and ISMR for the study period. Horizontal dotted line denotes the line $5 \%$ level significance.

have used the 31 years sliding window technique. In this technique, 31 years data of both (ISMR and $\mathrm{TI}_{1}$ and $\mathrm{TI}_{2}$ ) series are considered in a moving manner for calculating the CC. Figure 5 shows the variation of the CCs between the thermal indices with the ISMR during the period 1949-2012. The CC values are plotted against the middle year of the running windows. It is seen from Fig. 5 that the relationship between $\mathrm{TI}_{1}\left(\mathrm{TI}_{2}\right)$ with the ISMR is consistently positive (negative) and statistically significant throughout the period of analysis. However, there is a slight decrease in the strength of the relationship in case of $\mathrm{TI}_{2}$ in recent period. Here it may be noted that a study by Mandke and Bhide (2003) using data for the period 1901-1998 reported a significant change in various atmospheric parameters over the Bay of Bengal after 1980 during the summer monsoon period. The decreasing strength of the relationship of $\mathrm{TI}_{2}$ perhaps may be due to the change in various atmospheric variables even extending from pre-monsoon period also. It would be interesting to examine such variations during the pre-monsoon season also but this is beyond the scope of the present study. From the above analysis, it can clearly be concluded that the relationship is robust only in case of $\mathrm{TI}_{1}$ and hence we have not given much importance to $\mathrm{TI}_{2}$ for using it as a predictor of ISMR.

\section{4 $t$ value statistics based on difference of air temperature anomaly (flood minus drought) over $\mathbf{r 1}$}

Based on data from Indian stations, Verma (1980) indicated that the years with high upper tropospheric temperature anomalies over northern India during pre-monsoon months are generally associated with flood years. Tamura et al. (2010) observed that the upper tropospheric warming (during April-mid June) over the Tibetan Plateau is closely associated with the monsoon Hadley circulation. They mentioned that the Tibetan Plateau is heated not only by diabatic

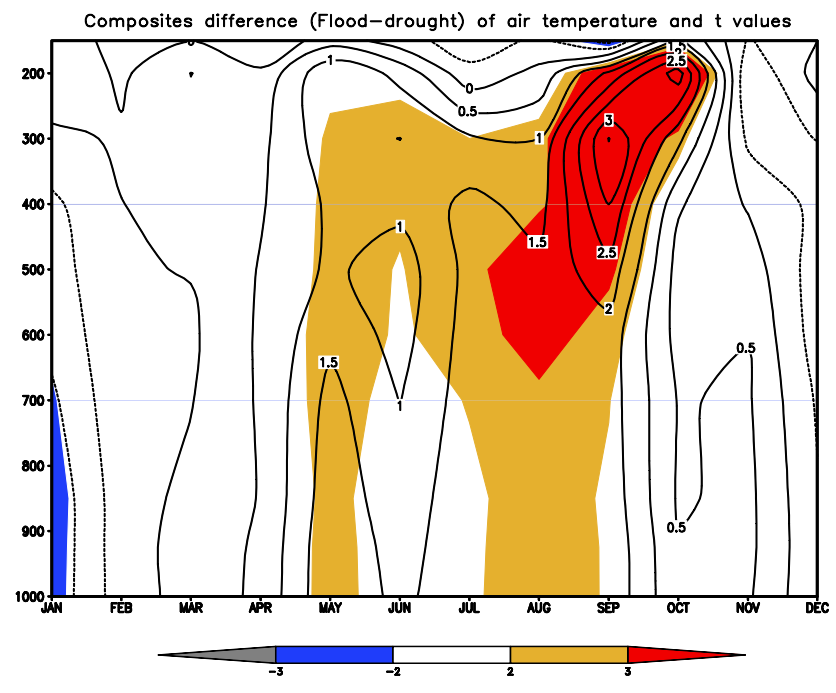

Figure 6. Vertical time variation of monthly composite difference (flood-drought) of air temperature anomalies for the months of January to December over region R1 (line contour plot) and $5 \%$ significant level $t$ values are plotted as shaded contour.

Table 1. Contingency table for frequency of occurrence of flood, drought and normal rainfall over India corresponding to warm, normal and cold temperatures over region $\mathrm{R} 1$.

\begin{tabular}{lrrr}
\hline & Flood & Normal & Drought \\
\hline Warm & 5.0 & 6.0 & 1.0 \\
Normal & 6.0 & 22.0 & 9.0 \\
Cold & 0.0 & 11.0 & 3.0 \\
\hline
\end{tabular}

chi-square $=8.571$

heating from the surface, but also by the adiabatic subsidence in the upper troposphere around the onset phase of the ASM. Hence to check the thermal characteristics of the whole troposphere, as an exercise we have evaluated $t$ statistics for the entire tropospheric column over the region $\mathrm{R} 1$. The $t$ values are deduced based on the difference of monthly composite temperature anomalies of flood and drought years for all the months from January to December. The Student $t$ test has been applied to check whether the observed feature has occurred merely by chance or if it has really given a true signal.

Figure 6 gives the vertical time section of $t$ values over R1 for the months January to December. Significant high positive $t$ values ( $>2$; significant at $1 \%$ level) are seen from 1000 to $300 \mathrm{hPa}$ level during the month of May as well as during the established period of summer monsoon. Although the values are significant up to upper tropospheric levels, the correlation analysis (as discussed in Sect. 2) suggested that the signal (based on $\mathrm{TI}_{1}$ ) is significant with maximum $\mathrm{CC}$ at $850 \mathrm{hPa}$ level. Hence the $t$ statistics support our hypothesis that $\mathrm{TI}_{1}$ can be used as a predictor for ISMR. 
To confirm further, we apply a chi-square $(\chi 2)$ test. For this purpose, we classified the $\mathrm{TI}_{1}$ for 63 years into cold, normal, and warm years as per criteria explained by Mason and Goddard (2001) and constructed the contingency table corresponding to the occurrence of drought, normal and flood years of ISMR which is shown in Table 1. It is seen that, in the case of warm events, there is only one drought year, but that of cold events, there are no flood years. Hence, the degree of certainty in the prediction of ISMR is increased for the case of cold events of the $\mathrm{TI}_{1}$. The null-hypothesis that is tested concerns these distribution results from random sampling fluctuations, and is not due to the influence of temperature anomalies over $\mathrm{R} 1\left(\mathrm{TI}_{1}\right)$. The results of $\chi 2$ presented through the contingency Table 1 show that the result for $\mathrm{TI}_{1}$ is found to be significant at $5 \%$ level. Hence, from the above discussion it can be inferred that $\mathrm{TI}_{1}$ can be considered as a predictor for flood and drought conditions over India with good confidence.

\section{Conclusions}

The interannual variation of the thermal field over the Asian summer monsoon region for lower tropospheric levels in relation to the ISMR has been brought out using correlation analysis and composite techniques based on data for the period 1949-2012. The following results are noteworthy.

1. A strong and significant northwest-southeast dipole structure in the correlation pattern is found over the Asian summer monsoon region between the temperature fields over the region during the month of May and the ISMR with highly significant positive (negative) correlations over the north India and western Tibetan Plateau regions (the north Bay of Bengal region).

2. The average air temperature over the north India and west Tibetan Plateau region during May at $850 \mathrm{hPa}$ level $\left(\mathrm{TI}_{1}\right)$ has a strong and stable relationship with the ISMR during the period of analysis.

3. The $t$ statistics based on composite annual cycle of the air temperature, along with the results of $\chi 2$ test, over the north India and west Tibetan Plateau region well supports the above result. The study has thus brought out that $\mathrm{TI}_{1}$ can be used as a predictor for the IMSR.

Acknowledgements. The authors are grateful to M. Rajeevan, Director, Indian Institute of Tropical Meteorology (IITM) Pune for providing the facilities and continuous encouragement during the course of the study. Thanks also due to NECP for availability of data and various products. We are also thankful to anonymous reviewers for their valuable suggestions for the improvement of the manuscript.

The topical editor V. Kotroni thanks three anonymous referees for help in evaluating this paper.

\section{References}

Bansod, S. D.: Lag-relationship between mid-tropospheric geopotential heights over the Northern Hemisphere and the Indian summer monsoon rainfall: Implications for forecasting, Theor. Appl. Climatol., 82, 143-152, 2005.

Ding, Q. and Wang, B.: Intraseasonal teleconnection between the Eurasian wavetrain and Indian summer monsoon, J. Climate, 20, 3751-3767, 2007.

Fadnavis, S. P., Chakraborty, T., Ghude, S. D., Beig, G., and Ernest, R. P.: Modulation of cyclone tracks in the Bay of Bengal by QBO, J. Atmos. Sol.-Terr. Phy., 73, 1868-1875, 2011.

Fadnavis, S. P., Raj, E., Buchunde, P., and Goswami, B. N.: In search of influence of stratospheric Quasi-Biennial Oscillation on tropical cyclones tracks over the Bay of Bengal region, Int. J Climatol., 34, 567-580, 2014.

Fujinami, H. and Yasunari, T.: The Effects of Midlatitude Waves over and around the Tibetan Plateau on Submonthly Variability of the East Asian Summer Monsoon, Mon. Weather Rev., 137, 2286-2304, 2009.

Joseph, P. V. and Srinivasan, J.: Rossby waves in May and the Indian summer monsoon rainfall, Tellus A, 51, 854-864, 1999.

Kalnay, E., Kanamitsu, M., Kister, R., Collins, W., Deaven, D., Gandin, L., Iredell, M., Saha, S., White, G., Woollen, J., Zhu, Y., Leetmaa, A., Reynolds, B., Chelliah, M., Ebisuzaki, W., Higgins, W., Janowiak, J., Mo, K. C., Ropelewski, C., Wang, J., Jenne, R., and Joseph, D.: The NCEP/NCAR 40-year reanalysis project, B. Am. Meteorol. Soc., 77, 437-471, 1996.

Kothawale, D. R. and Rupa Kumar, K.: Tropospheric temperature variation over India and links with the Indian summer monsoon: 1971-2000, Mausam, 53, 289-308, 2002.

Kripalani, R. H., Kulkarni, A., and Singh, S. V.: Association of the Indian summer monsoon with the northern hemisphere midlatitude circulation International, J. Climatol., 17, 1997, 10551067, 1997.

Kripalani, R. H., Kulkarni, A., and Sabade, S. S.: Western Himalayan snow cover and Indian monsoon rainfall:A reexamination with INSAT and NCEP-NCAR data, Theor. Appl Climatol., 74, 1-18, 2003.

Krishna, K. M.: Intensifying tropical cyclones over the North Indian Ocean during summer monsoon - Global warming, Global Planet. Change, 65, 12-16, 2009.

Krishnan, R., Kumar, V., Sugi, M., and Yoshimura, J.: Internal Feedbacks from Monsoon-Midlatitude Interactions during Droughts in the Indian Summer Monsoon, J. Atmos. Sci., 66, 553-578, 2009.

Li, C. and Yanai, M.: The onset and interannual variability of the Asian summer monsoon in relation to land-sea thermal contrast, J. Climate, 9, 358-375, 1996.

Liu, X. D. and Yanai, M.: Relationship between the Indian monsoon precipitation and the tropospheric temperature over the Eurasian continent, Q. J. Roy. Meteor. Soc., 127, 909-937, 2001.

Mahajan, P. N., Mujumdar, V. R., and Ghanekar, S. P.: Excitation of Low-level Jet as Seen by GOES (I-O) Satellite off the Somali Coast, Adv. Atmos. Sci., 6, 475-482, 1989.

Mandke, S. K. and Bhide, U. V.: A study of decreasing storm frequency over Bay of Bengal, J. Ind. Geophys. Union, 7, 55-58, 2003.

Mason, S. J. and Goddard, L.: Probabilistic precipitation anomalies associated with enso, Bull. Am. Meteor. Soc., 82, 619-638, 2001 
Mohanty, U. C., Dube, S. K., and Singh, M. P.: A study of heat and moisture budget over the Arabian Sea and their role in the onset and maintenance of summer monsoon, J. Meteorol. Soc. Jpn., 61, 208-221, 1983.

Mohanty, U. C., Bhatla, R., Raju, P. V. S., Madan, O. P., and Sarkar, A.: Meteorological fields variability over the Indian seas in pre and summer monsoon months during extreme monsoon seasons, J. Earth Syst. Sci., 111, 365-378, 2002.

Mooley, D. A. and Paolino, D. A.: A Predictive Monsoon Signal in the Surface Level Thermal Field over India, Mon. Weather Rev., 116, 256-264, 1988.

$\mathrm{Ng}$, E. K. W. and Chan, J. C. L.: Interannual variations of tropical cyclone activity over the north Indian Ocean, Int. J. Climatol., 32, 819-830, 2012.

Parthasarathy, B., Sontakke, N. A., Munot, A. A., and Kothawale, D. R.: Vagaries of Indian monsoon rainfall and its relationships with regional/global circulations, Mausam, 41, 301-308, 1990.

Pearce, R. P. and Mohanty, U. C.: Onsets of the summer Monsoon 1979-1982, J. Atmos. Sci., 41, 1620-1639, 1984.
Prasad, K. D., Bansod, S. D., and Sabade, S. S.: Forecasting Indian summer monsoon rainfall by outgoing longwave radiation over the Indian Ocean, Int. J. Climatol., 20, 105-114, 2000.

Rajeevan, M., Pai, D. S., and Thapliyal, V.: Spatial and temporal relationships between global and surface air temperature anomalies and Indian summer monsoon, Meteorol. Atmos. Phys., 66, 157-171, 1998.

Tamura, T., Taniguchi, K., and Koike T.: Mechanism of upper tropospheric warming around the Tibetan Plateau at the onset phase of the Asian summer monsoon, J. Geophys. Res., 115, D02106, doi:10.1029/2008JD011678, 2010.

Verma, R. K.: Importance of the upper tropospheric thermal anomalies for long range forecasting in Indian summer monsoon activity, Mon. Weather Rev., 108, 1072-1075, 1980.

Verma, R. K.: Long-range prediction of monsoon activity - a synoptic diagnostic study, Mausam, 33, 35-44, 1982.

Watanabe, T. and Yamazaki, K.: Influence of the Anticyclonic Anomaly in the Subtropical Jet over the Western Tibetan Plateau on the Intraseasonal Variability of the Summer Asian Monsoon in Early Summer, J. Climate, 2, 1291-1303, 2012. 